\title{
Corrigendum: The role of action representations in thematic object relations
}

\author{
Konstantinos Tsagkaridis ${ }^{1 *}$, Christine E. Watson ${ }^{2}$, Steven A. Jax ${ }^{3}$ and Laurel J. Buxbaum ${ }^{2 *}$ \\ ${ }^{1}$ Department of Psychology, School of Humanities and Health Sciences, Neapolis University Pafos, Pafos, Cyprus, \\ ${ }^{2}$ Cognition and Action Laboratory, Moss Rehabilitation Research Institute, Einstein Healthcare Network, Philadelphia, PA, \\ USA, ${ }^{3}$ Perceptual-Motor Control Laboratory, Moss Rehabilitation Research Institute, Einstein Healthcare Network, \\ Philadelphia, PA, USA
}

Keywords: semantic, action, thematic, taxonomic, apraxia, stroke, embodied cognition, object relations

\section{A corrigendum on}

The role of action representations in thematic object relations by Tsagkaridis, K., Watson, C. E., Jax, S. A., and Buxbaum, L. J. (2014) Front. Hum. Neurosci. 8:140. doi: 10.3389/fnhum.2014.00140

We wish to correct a typo on page 7, in the last paragraph of the RESULTS section called "Choice Data" and just before the beginning of the paragraph called "Modeling choices based on object pair ratings-Group differences."

The mistake is in lines 3 and 5 of this paragraph in the PDF version of the article, where the printed name Th-A should be changed to Th+A. The term Th-A in the last line of the paragraph is correct.

For this correction, the whole paragraph should be written as follows:

OPEN ACCESS

Edited and reviewed by: Hauke R. Heekeren, Freie Universität Berlin, Germany

*Correspondence: Konstantinos Tsagkaridis k.tsagkaridis@nup.ac.cy;

Laurel J. Buxbaum

Ibuxbaum@einstein.edu

Received: 19 August 2015 Accepted: 18 September 2015 Published: 29 September 2015

Citation:

Tsagkaridis K, Watson CE, Jax SA and Buxbaum LJ (2015) Corrigendum: The role of action representations in thematic object relations.

Front. Hum. Neurosci. 9:548. doi: 10.3389/fnhum.2015.00548
"In short, these analyses revealed that when we considered Th+A vs. Th-A triads in particular, Posterior patients were less likely to choose the $\mathrm{Th}+\mathrm{A}$ pair relative to controls. Posterior patients also tended to be less likely than Anterior patients to choose the Th+A option, though this difference was only marginally significant. Finally, Posterior participants made more Th-A choices overall relative to Controls."

The original article was updated.

\section{Acknowledgments}

This work was supported by an NIH award R01 NS065049 and James S. McDonnell Foundation award \#220020190 to LB.

Conflict of Interest Statement: The authors declare that the research was conducted in the absence of any commercial or financial relationships that could be construed as a potential conflict of interest.

Copyright $\odot 2015$ Tsagkaridis, Watson, Jax and Buxbaum. This is an open-access article distributed under the terms of the Creative Commons Attribution License (CC BY). The use, distribution or reproduction in other forums is permitted, provided the original author(s) or licensor are credited and that the original publication in this journal is cited, in accordance with accepted academic practice. No use, distribution or reproduction is permitted which does not comply with these terms. 